\title{
PENDIDIKAN SEKS UNTUK ANAK USIA SEKOLAH DASAR DALAM PERSEFEKTIF ISLAM
}

\author{
Aang Mahyani
}

Kata seksdalamKamus Besar Bahasa Indonesia sering diartikan dengan jenis kelamin, yaitu laki-laki dan perempuan. Dalam bahasaInggris, seks berarti jenis kelamin, perkelaminan. Dalam bahasa Arab, seks diartikan jins (جنس ) yang berarti jenis kelamin atau setiap yang berkaitan dengan bentuk tubuh.Seks adalah Syahwat berasal dari kata mengandung arti menyukai atau menyenangi. Jika dihubungkan dengan manusia, maka syahwat artinya kerinduan nafs (jiwa) terhadap apa yang dikehendaki. Dalam al-Quran, kalimat syahwat dalam berbagai bentuknya sebanyak 13 kali, 5 kali diantaranya dalam bentuk masdar, yakni 2 kali mufrad dan tiga kali jama. Al-Qur'an menggunakan termsyahwat untuk beberapa arti. Pertama, dalam kaitannya dengan fikiran-fikiran tertentu, yakni mengikuti pikiran orang lain karena mengikuti hawa nafsu \{Q.S. an-Nisâ [4]:27\}, Kedua, dihubungkan dengan keinginan manusia terhadap kelezatan dan kesenangan \{Q.S. ali-Imran [3]:14 dan Maryam [7] :59\}. Ketiga, berhubungan dengan perilaku seks menyimpang. Pendidikan seks adalah pendidikan akhlak. Pendidikan seks bagi anakbahwa pendidikan seks tidak terbatas pada usia baligh. Islam menetapkan untuk melatih anak agar dapat beradaptasi secara baik dengan sikap-sikap seksual sejak usia tamyiz yang tidak ditentukan syariat secara detail karena perbedaan-perbedaan individual diantara anak-anak dalam pertumbuhan intelektualitasnya. Namun orang tua dan semua pendidik, melalui interaksi dengannya, mengetahui bahwa seorang anak sudah mulai memikirkan hal itu (masalah seksual) atau belum memikirkannya pada usia tamyiz. Pendidikan Seks dalam rumah tanggabahwa rumah tangga yang baik, jika sejak awal pernikahan dibangun dengan dasar-dasar dan pertimbangan yang benar sesuai dengan ajaran agama Islam. Tujuan pendidikan seks menurut adalah agar manusia dapat mengatur kehidupan seksualnya sejak lahir hingga dewasa, dalam pergaulan baik sejenis maupun lawan jenis, perkawinan, etika pakaian, pergaulan, ibadah dan kebersihan yang berdasarkan iman yang diatur dalam Islam

\section{Kata Kunci: Islam, Pendidikan, Pendidikan Seks}

\section{PENDAHULUAN}

Pada dasarnya pendidikan seks yang terbaik adalah yang diberikan oleh kedua orang tua sendiri. Diwujudkan melalui cara hidup orang tua dalam keluarga sebagai suami-istri yang bersatu dalam perkawinan. Pendidikan seks ini sebaiknya diberikan dalam suasana akrab dan terbuka dari hati ke hati antara orang tua dan anak. Kesulitan yang timbul kemudian adalah apabila pengetahuan orang tua kurang memadai (secara teoritis dan objektif) menyebabkan sikap kurang terbuka dan cenderung tidak memberikan pemahaman tentang masalah-masalah seks anak.
Akibatnya anak mendapatkan informasi seks yang tidak sehat.

Dalam perspektif Islam manusia dipandang memiliki hawa nafsu yang bersumber dari fitrahnya yang dibawa sejak lahir, dalam ilmu pendidikan manusia menjadi objek pembahasan yang paling utama, karena dalam pandangan pedidikan manusia bukan hanya objek tetapi sekaligus menjadi subjek dari pendidikan. Ada beberapa definisi yang disusun oleh para ahli pendidikan dari berbagai disiflin ilmu tentang hakikat 
manusia, misalnya manusia disefinisikan sebagai "Homo Faber" yaitu manusia yang mampu membuat peralatan, Homo Sapiens" manusia yang mampu mempergunakan pemikirannya dan Homo Ludeus" manusia yang bermain. ${ }^{1}$

Manusia tidak akan mampu melepaskan diri dalam hal kehidupan yang berkaitan dengan masalah seksual karena masalah seksual ini bagian dari naluri yang ada pada manusia serta menjadi kebutuhan bagi dirinya. Allah Swt telah menyatakan dalam al-quran bahwa manusia terhadap seksual sudah menjadi kesenangan, Q.S. Ali [3]: $14 .^{2}$

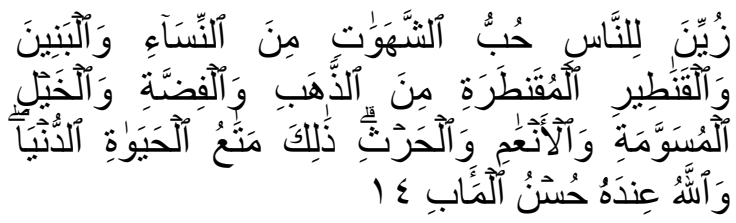

Dijadikan indah pada (pandangan) manusia kecintaan kepada apa-apa yang diingini, yaitu: wanita-wanita, anak-anak, harta yang banyak dari jenis emas, perak, kuda pilihan, binatang-binatang ternak dan sawah ladang. Itulah kesenangan hidup di dunia, dan di sisi Allah-lah tempat kembali yang baik (surga).

Di samping ruh, manusia diberi ruang yang dapat digunakan untuk merealisasikan suatu keinginan atau kegembiraan di dalam dirinya. Allah SWT menjelaskan kepada umat-Nya secara tersurat dalam Q.S. Thâhâ [20]:50 dan Q.S. al-Furqân [25]:2, ${ }^{3}$

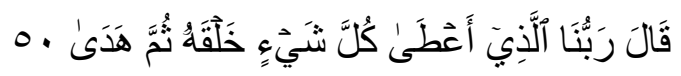

${ }^{1}$ Erich From Menganggap bahwa pemahaman tentang "Homo Sapiens" tidak cukup pada pemahamahan bahwa Homo Sapiens itu adalah manusia yang mamapu mempergunakan pemikirannya untuk memperoleh barang-barang yang berguna bagi kelangsungan hidupnya, sebab menurut dia ada perbedaan kualitatif antara manusia dengan hewan. Kalau Homo Sapiens diartikan seperti tersebut di atas maka hewan pun akan mampu, tetapi Homo Sapiens lebih diartikan sebagai manusia yang mampu memfokuskan pikiranya dari bentuk lahir yang memberdayakan kepada yang "sunggu-sungguh rill" Jogjakarta;Pustaka pelajar 1999: h.58

${ }^{2}$ Al-Quran dan Terjemahnya

${ }^{3} \mathrm{Al}-\mathrm{Quran}$ dan Terjemahnya
Musa berkata: "Tuhan kami ialah (Tuhan) yang telah memberikan kepada tiap-tiap sesuatu bentuk kejadiannya, kemudian memberinya petunjuk

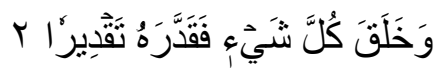

dan Dia telah menciptakan segala sesuatu, dan Dia menetapkan ukuran-ukurannya dengan serapi-rapinya.

Memang tidak dapat dipungkiri bahwa nafsu seksual merupakan fondasi bagi perkembangan kepribadian manusia. Akan tetapi nafsu seksual juga dapat menjadi sumber problema yang pelik bagi manusia, yaitu apabila keinginan dan nafsunya itu cenderung lepas kontrol dan tidak terkendali, maka akan menyeret manusia ke jalan kejahatan. Dorongan atau hasrat untuk melakukan hubungan seks selalu muncul jauh lebih awal daripada kesempatan untuk melakukan secara bebas, inilah yang banyak terjadi pada remaja ${ }^{4}$. Pada fase ini remaja mencapai tahapankematangan organ-organ seks. ${ }^{5}$

Aktivitas seksual yang dilakukan terlalu dini oleh remaja disebabkan karena dua faktor, faktor interen kondisi gizi yang baik pada anak-anak sekarang

\footnotetext{
${ }^{4}$ Manusia pada fase remaja menyimpan potensi seksual dan emosional yang tinggi. Bahkan masa-masa ini merupakan masa yang paling beresiko dalam kehidupan manusia. Sebab emosi, naluri seks, dan dorongan syahwat sedang berada pada puncak yang tinggi dan menggebu-gebu. Zat-zat yang diproduksi oleh tubuh sangat dominan dalam menggerakkan dan meningkatkan emosi, naluri seks, dan dorongan syahwat. Sehingga sisi-sisi ini kelihatan menonjol ketimbang yang lainnya, sedangkan akal dan logika berpikir remaja pada umumnya masih berada pada tahap pertumbuhan. Dalam kondisi seperti ini, mereka membutuhkan bimbingan yang dapat mereka terima dengan pikiran dan hati mereka sebagai remaja. Muhammad al-Zuhaili, Menciptakan Remaja Dambaaan Allah (Terjmh: al- Islâm wa al-Syabâb), (Bandung: Mizan, 2004), Cet ke-1, h. 123

${ }^{5}$ Menurut Singgih D.Gunarsa munculnya kematangan organ seks dan dilaksanakannya hubungan seks mempunyai beberapa fungsi, yaitu; untuk melanjutkan keturunan (fungsi reproduktif). untuk mempersatukan dua anak manusia dalam lembaga perkawinan. Hubungan seks diluar tujuan dan fungsi tersebut diatas hanyalah berdasarkan pada prinsip kenikmatan (bagi yang menikmatinya) atau prinsip lain dengan tujuan tersamar atau terselubung (misalnya karena dendam), pelarian (kesal hati) ekonomi (sex exploitation) dan petualangan (misalnya pada remaja dengan keinginan mengetahui dan keinginan yang besar untuk mencoba). Lihat Singgih D. Gunarsa, et. al, Psikologi Praktis; Anak, Remaja dan Keluarga, (Jakarta: BPK Gunung Mulia, 2000), Cet . IV, h. 92. Singgih D. Gunarsa, et. al, h. 91
} 
membuat terjadinya percepatan kematangan fisik termasuk organ-organ seksual. Bahkan sekarang ini anak kelas empat SD sudah dapat haid (menstruasi). Sehingga naluri seksual mereka muncul lebih cepat dibandingkan dengan kondisi mentalnya yang belum berkembang secara sempurna. ${ }^{6}$

Faktor Ekstern semakin pesatnya perkembangan teknologi dan alat-alat komunikasi, terjadilahperubahan-perubahan sosial yang diakibatkan oleh bervariasinya ide-ide ekonomi, religi, dan ilmu pengetahuan, sehingga mempengaruhi adat kehidupan manusia, yang sekaligus juga mempengaruhi pola-pola seks yang konvensial. Ditambah lagi semakin terbuka dalam berbagai bentuk, lewat buku-buku, majalah-majalah, ${ }^{7}$

Untuk menjawab permasalahanpermasalahan di atas yang lebih relevan dengan perkembangan zaman yang dengan mengembangkan pendidikan seks yang akan mendorong anak memiliki pengetahuan tentang seks yang benar, yakni mendorong pengembalian kesucian seks sehingga seks hanya boleh dilakukan dalam lembaga pernikahan. Keingintahuan anak tidak boleh diabaikan, namun juga harus dijawab tidak dengan cara yang akan mendorong anak terlibat dalam aktivitas seksual, melainkan dengan cara yang menjadikannya dengan pengetahuan yang memadai menghormati perilaku seks

\footnotetext{
${ }^{6}$ Istanti Surviani, Membimbing Anak Memahami Masalah Seks, (Bandung: Pustaka Ulumuddin, 2004), Cet. I, h. 47

Salah satunya majalah HAI, majalah pria yang sangat populer. Apa yang disampaikannya sangat berpotensi mempengaruhi perilaku atau nilai-nilai yang dianut pembacanya. Masalahnya, para anggota redaksi majalah tersebut menganut nilai-nilai seksual yang sangat bebas. Semangat kebebasan itu terasa di sepanjang edisi yang menyajikan tema utama 'Seks di luar Nikah'. Sebagai contoh, dalam salah satu artikel, tertulis pengantar: 'Premarital seks sebaiknya jangan dilakuin. Bukan apa-apa, resikonya berat. Tapi kalau udah nggak tahan lagi dan nekat, ya terserah'. Lihat Kata pengantar oleh Ade Armando dalam karya Shahid Athar, Bimbingan Seks Bagi Remaja Muslim, (Jakarta: Pustaka Zahra, 2003), h. xiv-xv
}

sebagai sebuah rahmat Allah yang suci. Anak harus tahu bahwa seks adalah serius, dan perilaku seks memiliki dampak sangat serius terhadap kehidupan setiap individu atau masyarakat. Sedini mungkin orangtua memberikan informasi tentang masalah seksual, agar anak tidak mencari informasi dari orang lain atau sumber-sumber yang tidak jelas atau bahkan keliru sama sekali. Pemberian informasi masalah seksual yang keliru, misalnya: diketahui dari penjelasan teman (yang belum tentu benar), membaca buku-buku porno, melihat gambar-gambar porno dari buku maupun internet, bisa juga dari penjelasan yang kurang lengkap dari orangtua.Semua pengetahuan yang serba tanggung ini, justru membuat banyak remaja malah mencari tahu dengan cara melakukannya sendiri. Dan hal ini akan sangat berbahaya bagi perkembangan jiwa remaja. Fakta menunjukkan bahwa sebagian besar remaja kita tidak mengetahui dampak dari perilaku seksual yang mereka lakukan. Seringkali remaja sangat tidak matang untuk melakukan hubungan seksual terlebih lagi jika harus menanggung resiko dari hubungan seksual tersebut. ${ }^{8}$

\section{LANDASAN PENDIDIKAN SEKS}

Kata seks dalamKamus Besar Bahasa Indonesia sering diartikan dengan jenis kelamin, yaitu laki-laki dan perempuan. ${ }^{9}$ Dalam bahasa Inggris, seks berarti jenis kelamin, perkelaminan. ${ }^{10}$ Dalam bahasa Arab, seks diartikan jins (جنس yang berarti jenis kelamin atau

${ }^{8}$ Dalam melakukan hubungan seksual sebagian remaja tidak terlindung dari dua kemungkinan yang dapat terjadi yaitu kehamilan yang tidak dikehendaki dan penyakit hubungan seksual yang dapat menjurus ke arah penyakit radang panggul (PRP) atau pelvic inflamantory diseases (PID). Dua masalah ini menjadi topik utama yang dihadapi remaja dalam mencari identitas yang akanmenjerumuskan remaja kepada kesulitan pemecahan masalah. lihat: http: //www. E-Psikologi. Com diakses pada tanggal 12 Maret 2013

${ }^{9}$ Departemen P \& K , Kamus Besar Bahasa Indonesia, (Jakarta: Balai Pustaka, 1996), Edisi ke.II, h. 893

${ }^{10}$ John M. Echols, et.al, Kamus Inggris-Indonesia, (Jakarta: PT.Gramedia, 1996), Cet XXIII, h. 517 
setiap yang berkaitan dengan bentuk tubuh. ${ }^{11}$

James

Drever

dalam

bukunyaDictionary Of Physicology, berpendapat bahwa seks adalah suatu perbedaan mendasar yang berhubungan dengan reproduksi dalam satu jenis yang membagi jenis ini menjadi dua bagian, yaitu jantan dan betina sesuai dengan sperma (jantan) dan sel telur (betina) yang diproduksi. ${ }^{12}$ Senada dengan Drever, Abu Zakaria memberi pengertian bahwa seks adalah hubungan kelamin antara jantan dan betina atau secara harfiah perkelaminan atau kelamin. ${ }^{13}$

$$
\text { Syafiq Hasyim lebih }
$$

menitikberatkan perbedaan antaraseks dan gender. Menurutnyaseks biasanya diterjemahkan dengan jenis kelamin yang bersifat biologis. Misalnya seseorang disebut laki-laki karena secara biologis memiliki penis demikian juga seseorang disebut perempuan karena memiliki vagina. Sedangkangender sering juga diterjemahkan jenis kelamin, tapi bukan berkaitan dengan faktor-faktor biologis melainkan dengan faktor-faktor sosial.Nasaruddin Umar dalam mengartikanseks, lebih banyak berkonsentrasi kepada aspek biologis seseorang, meliputi perbedaan komposisi kimia dan hormone dalam tubuh, anatomi fisik, reproduksi, dan karakter biologis lainnya. Dan seks secara umum digunakan untuk mengidentifikasi perbedaan laki-laki dan perempuan dari segi anatomi biologis, seks umumnya

\footnotetext{
${ }^{11}$ As'ad al-Kalali, Kamus Indonesia -Arab, (Jakarta: Bulan Bintang, 1997), Cet VII, h. 484

${ }^{12}$ Dalam teori psikoanalisa, seks dan seksual diperluas agar mencakup fenomena yang tidak mempunyai sikap langsung kepada reproduksi, dengan anggapan bahwa kenikmatan yang didapat adalah dari susunan yang sama, yang sesungguhnya sama pentingnya, dalam kasus khusus dengan anak kecil, seperti yang dihubungkan dengan fenomena seks dalam arti yang sempit; jika dalam kasus- kasus seperti itu, sensuous digantikan dengan seksual, dan banyak pandangan mereka yang lebih siap diterima. Lihat James Drever, Dictionary of Physicology, (Jakarta: PT. Bina Aksara, 1988), Cet. II, h. 439

${ }^{13}$ Abu Zakaria, Mengawetkan Cinta Kasih Suami Istri, (Solo: Aneka, 1990), h. 10
}

digunakan untuk merujuk kepada persoalan reproduksi dan aktivitas seksual (love making activities). ${ }^{14}$

Shâhid

Athâr

dalam

bukunyaBimbingan Seks bagi Remaja Muslim, menyatakan bahwa seks merupakan proses hubungan intim antara dua orang yang berlainan jenis kelamin atau yang memiliki jenis kelamin yang sama (homoseksual), ${ }^{15}$

Berdasarkan uraian diatas, dapat disimpulkan bahwa seks secara harfiah atau secara sempit, dalam ketiga bahasa, baik bahasa Indonesia, Inggris dan Arab, sama-sama mengartikan seks dengan "kelamin", yang meliputi: (1) alat kelamin itu sendiri; (2) anggota-anggota tubuh serta ciri-ciri badan lainnya yang membedakan laki-laki dan wanita; dan (3) kelenjar-kelenjar, libido (nafsu syahwat), serta hormon-hormon dalam tubuh yang mempengaruhi bekerjanya alat kelamin.

Sedangkan seks dalam arti yang luas yaitu segala hal yang terjadi sebagai akibat adanya perbedaan jenis kelamin, antara lain: (1) perbedaan tingkah laku (lembut, kasar, genit, dan lain-lain); (2) perbedaan atribut; (3) perbedaan peran dan pekerjaan;(4) hubungan antara pria dan wanita (tata krama pergaulan, percintaan, pacaran, perkawinan, dan lain-lain); dan (5) hubungan kelamin (senggama, percumbuan, coitus).

Dari istilah seks terlahir istilahistilah antara lain; Sensualitas berarti segala sesuatu yang berkenaan dengan

\footnotetext{
${ }^{14}$ Nasaruddin Umar, Kodrat Perempuan dalam Islam, (Jakarta: Fikahati Aneska, 2000), Cet. I, h. 10-12

${ }^{15}$ Homoseksual adalah aktivitas seksual yang dilakukan oleh laki-laki dengan laki-laki. Dalam istilah lain kaum homoseks ini sering disebut kaum gay. Konon jumlah kaum gay ini lebih besar dibandingkan dengan kaum lesbian, yaitu sekitar 3-4 kali lipat. Ada empat sebab mengapa seseorang menjadi homoseks. Pertama, faktor herediter atau bawaan dimana dalam tubuh laki-laki terjadi Pertama, ketidakseimbangan hormon-hormon seksnya. Kedua, pengaruh lingkungan seks yang tidak baik bagi perkembangan seksual yang normal. Ketiga, pernah memiliki pengalaman homoseksual memuaskan pada masa remaja. Keempat, pengalaman traumatis dengan ibunya sehingga menimbulkan antipati dan kebencian terhadap ibu dan perempuan lain. Lihat Marzuki Umar Sa'abah, Seks dan Realita, (Jakarta: Gema Insani Press, t,th), h. 147.
} 
perihal fisik. Sensual adalah kenikmatankenikmatan yang bersifat naluriah, seperti rasa senang menikmati makanan, minuman, atau hubungan seksual. Seksualitas adalah ciri-ciri, sifat, peranan seks, dorongan seks, dan kehidupan seks. ${ }^{16}$ Sexiness, yang berarti hal-hal yang dapat merangsang nafsu seks. Istilah lain adalah sexs appeal, yaitu daya tarik yang kuat yang dapat membangkitkan serta merangsang seseorang pada nafsu-nafsu seksual. ${ }^{17}$ Selain itu, terdapat kata Seksuil, yaitu istilah yang berasal dari bahasa latin yang maksudnya adalah sesuatu yang berkenaan dengan jenis kelamin (laki-laki atau perempuan), yang berkenaan dengan perkara percampuran antara laki-laki dan perempuan. $^{18}$

\section{TAHAPAN PERKEMBANGAN SEKS}

Adapun tahapan psikoseksual yang harus dilalui seseorang dari usia balita hingga remaja menurut Sigmund Freud ${ }^{19}$ terbagi dalam 5 (lima) fase, yaitu: ${ }^{20}$

1. Fase oral (Oral Stage)

Fase oral ${ }^{21}$ adalah fase seorang anak

\footnotetext{
${ }^{16}$ Departemen P \& K, Kamus Besar Bahasa Indonesia, h. 893

${ }^{17}$ Peter Salim, Advanted English-Indonesia Dictionary, (Jakarta: Modern English Press, 1993), Edisi keempat, h. 770

${ }^{18}$ WJS. Poerwadarminta, Kamus Umum Bahasa Indonesia, (Jakarta: Balai Pustaka, 1985),Cet ke-VIII, h. 980. Lihat juga Departemen P \& K , Kamus Besar Bahasa Indonesia, h. 796-797

${ }^{19}$ Sigmund Freud seorang dokter Austria yang dilahirkan pada tahun 1856 di Maurovia. Ayah ibunya orang Yahudi. Setelah belajar kedokteran ia menggeluti bidang psikoanalisa. Baca: Hayâtî waal-Tahlîl al-Nafsi (Hidupku dan Psikoanalisa) dan Tsalâtsah Maqâlat fi Nadhoriyyah al-Jins (Tiga Kajian Tentang Teori Seks). Sebagaimana dikutip Dr. Mustafầ Abdul Wahid, Islam dan Anarsisme Seks, (Yo19 yakarta: Al-Kautsar, 1990), Cet .I, h. 16

${ }^{20}$ Ajen Dianawati, Pendidikan Seks Untuk Remaja, (Tangerang: Kawan Pustaka, 2003), Cet.II, h. 2-3. Lihat juga Ali Akbar dan Yusuf Abdullah Puar, Bimbingan Sex Untuk Remaja, (Jakarta: Pustaka Antara, 1996), Cet.IX, h.13. Lihat http ://www.iqeq.web.id/remaja/remaja5.shtml

${ }^{21}$ Term oral menurut etimologi berarti mulut. Dalam bahasa Arab disebut al-lisân (jama dari alsinatun waalsunun). Segala sesuatu dengan menggunakan mulut. Lihat Ahmad Warson Munawwir, al-Munawwir; Kamus Bahasa Arab-Indonesia, (Yogyakarta: Pondok Pesantren al-Munawwir, 1984), h. 1359. Lihat juga Peter Salim, The Contemporary English-Indonesia: Dictionary, (Jakarta: Modern English Press, 1996), h. 1305. John M.Echols, Kamus Inggris-Indonesia, h.407
}

mendapatkan perasaan nikmat melalui mulutnya, yaitu ketika sedang menyusu dan mengisap air susu melalui putting susu ibunya. Fase ini dimulai sejak bayi hingga usia antara 0-2 tahun. Pada usia ini seorang anak terlihat sangat antusias memasukkan apa saja ke dalam mulutnya. Hal itu merupakan tahap awal pemenuhan dari perkembangan psikoseksual dalam dirinya.

\section{Fase Anal (Anal Stage)}

Pada fase anal, kenikmatan yang dirasakannya berubah dari mulut ke daerah anus dan sekitarnya (seperti saluran kencing). Rasa nikmat dan puas dirasakan ketika anak sedang menahan kencing dan buang air besar. Fase ini dimulai pada saat anak berusia 2-3 tahun.

\section{Fase Phallus (Phaliic Stage)}

Selanjutnya perubahan yang dirasakannya turun ke bagian alat kelaminnya. Fase phallus ini berlangsung pada saat anak memasuki usia 3-7 tahun. Rasa nikmat yang dirasakan berlangsung ketika alat kelaminnya mengalami sentuhan atau rabaan. Bahkan ada beberapa anak pada fase ini yang dengan sengaja menyentuh alat kelaminnya untuk mencapai orgasme (tentu saja tidak disertai ejakulasi).

\section{Fase Laten (Latency Stage)}

Terjadi sekitar umur 7-11 tahun. Pada fase ini, tingkah laku seksual seorang anak seolah-olah terpendam. Karena mungkin lebih banyak bermain, mulai masuk sekolah, dan adanya pekerjaan rumah dan sekolah. Sehingga mereka cepat lelah dan lekas tertidur, karena untuk persiapan bangun pagi dan pergi sekolah.

\section{Fase Genital (Genita Stage)}

Fase ini terjadi pada usia 12- dewasa, tanda sekunder mulai berkembang. Pada seorang wanita fase ini ditandai dengan mengalami menstruasi pertama dan pada pria dengan pengalaman mimpi basah, sehingga dapat menyebabkan kehamilan bila mereka melakukan hubungan seksual. Keinginan seks dalam bentuk libido mulai 
tampak dan terus berlangsung sampai mencapai usia lanjut. Daya tarik seksual, sosialisasi, kegiatan-kegiatan kelompok, perencanaan karier, dan persiapan untuk menikah mulai muncul.

\section{PANDANGAN ISLAM TENTANG SEKS}

Pada dasarnya Islam mengakui bahwa kebutuhan seks adalah kebutuhan manusiawi dan Islam percaya bahwa kebutuhan itu harus dipelihara, bukan ditindas. Firman Allah Q.S. al-Mu'minun [23]:115 ${ }^{22}$, Tidak ada satunash dalam alQur'an atau Hadits pun yang menyatakan bahwa menyalurkan kebutuhan seks itu sebuah kejahatan dan dosa. Al-Qur'an berbicara mengenai seks dan tidak dianggap sebagai permasalahan yang tabu, terbukti dengan berbagai term (istilah) yang digunakan dalam mengilustrasikan dan menjelaskan yang berkenaan dengan permasalahan seks, misalnya ar-Rafats, yang berarti percumbuan ${ }^{23}$, termaktub dalam QS. al-Baqarah [2] : 187.

Sebagaimana Sigmund Freud yang berpendapat bahwa manusia sangat dipengaruhi oleh kekuatan-kekuatan bawah sadar, termasuk dorongan seksual. Jika dorongan- dorongan untuk memuaskan kebutuhan-kebutuhan itu ditekan, maka akanmemunculkan kekacauan kepribadian, termasuk perilaku-perilaku menyimpang, kelainan seksual $^{24}$ serta kecenderungan pada

${ }^{22}$ Q.S. al-Mu'minun [23]: 115

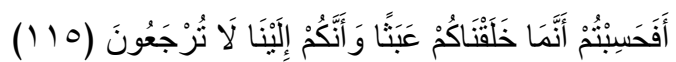

Maka Apakah kamu mengira, bahwa Sesungguhnya Kami menciptakan kamu secara main-main (saja), dan bahwa kamu tidak akan dikembalikan kepada kami?

${ }^{23}$ Muhammad S.Djarot S.Sensa, Seks dalam Islam, (Bandung: Sinar Baru, 1993), Cet.I, h. 22

${ }^{24}$ Kelainan seksual adalah cara yang ditempuh seseorang untuk mendapatkan kenikmatan seksual dengan jalan tidak sewajarnya. Biasanya, cara yang ditempuh oleh orang tersebut adalah dengan menggunakan obyek seks yang tidak wajar. Penyebab terjadinya kelainan ini bersifat psikologis atau kejiwaan, seperti pengalaman sewaktu kecil, lingkungan pergaulan, trauma dan kelainan genetika. Islam juga mengutuk berbagai penyimpangan dalam hubungan seksual, seperti kriminalitas. Dan lebih ekstrem, Freud menyatakan bahwa nafsu seks merupakan penggerak satu-satunya dalam tingkah laku dan perbuatan manusia. Menurutnya, semua kesenangan atau kegembiraan bersumber kepada dorongan seks yang berfungsi sejak lahir dalam bentuk tertentu. $^{25}$

Islam jelas berbeda dengan kapitalisme dengan paham kebebasannya. Islam dalam menyikapi seks sebagai sebuah kerja rohani yang membedakan manusia dengan hewan. Hewan kapan dan dimana saja ketika hasratnya bangkit, bias dilampiaskan dengan sesuka hati. Artinya, apa bedanya manusia dengan hewan jika kemudian setiap hasrat seks bangkit langsung dicarikan tempat pelampiasannya begitu saja. ${ }^{26}$ Karena itu dalam Islam, seluruh tingkah laku manusia wajib terikat pada aturan-aturan Allah SWT yang Maha Pengasih dan Penyayang. Aturan Allah SWT jelas akan memberikan kebaikan pada manusia, sebab Allah SWT yang paling tahu tentang apa yang paling baik untuk manusia. Sangat jelas, saat manusia lalai dari aturan Allah, munculnya penderitaan, antara lain penyakit seksual. ${ }^{27}$

seperti homoseksualitas, yaitu hubungan seks bagi orang-orang yang sejenis, seperti sesama laki-laki atau sesama perempuan. Sebagaimana firman Allah QS. al-'Araf [7]: 80-84, yang mengutuk kaum Nabi Luth yang menyukai sesama jenis (homoseks), masochism (laki-laki mencari kepuasan seksual dengan cara disiksa dan dipukul oleh wanita pasangannya), sadisme (lawan dari masochisme, laki-laki mendapat kepuasan seksual dengan jalan menyiksa wanita pasangannya), dan voyeurisme (mencari kepuasan seksual dengan cara mengintip perempuan telanjang, sedang mandi atau berganti pakaian).

${ }^{25}$ Sebagaimana yang dikutip oleh Sumadi Suryabrata, Psikologi Kepribadian, (Jakarta: Giri Mukti Pustaka, 1984), h. 145 - 149

${ }^{26}$ Iip Wijayanto memberikan cara dalam mengendalikan dorongan seksual ada dua macam: Pertama, Manajemen seks adalah sebuah upaya untuk mengelola aktivitas seks. Kedua, Manajemen Hasrat Seksual, adalah hasrat itu erat kaitannya dengan rasa, dan rasa itu berdasar konsensus nilai paradigmatik. Pengelolaan hasrat seks harus dimulai dari pengelolaan pikiran dan akal, yang diajak untuk mempersepsikan seks dengan baik. Lihat lip Wijayanto, Pemerkosaan atas Nama Cinta; Potret Muram Interaksi Sosial, (Yogyakarta: Kelompok Penerbit Qalam/TINTA, 2003),Cet.I, h. 87-88

${ }^{27}$ Manusia akan tetap menjadi makhluk yang terhormat, selama ia mematuhi segala peraturan yang diberikan Allah kepadanya, tetapi ia akan menjadi rendah dan lebih hina dari 
Islam mengatur bagaimana hubungan pria dan wanita yang aman, yakni melalui ikatan perkawinan yang sah. Tidak hanya itu, Islam pun menutup segala jalan yang mengakibatkan munculnya kebebasan seksual yang berbahaya. Islam melarang umatnya untuk mendekati perbuatan zina. Firman Allah QS. al-Isrâ [17]: 32.

Diantaralaranganmendekatizina ${ }^{28}, \mathrm{mi}$ salnyaIslammelarangpria wanita berinteraksisecarabebaskecualidalam halhalyang dibolehkanolehsyari'i.Campur aduk

(ikhtilat)adalahperkarayangdiharamkandal amIslam.Sehingga,Islam meminimalkan hubungan pria dan wanita, kecuali dalam perkara-perkara tertentu sepertijual beli,pendidikan,pengadilan,kesehatandani nteraksilainyangmemang membutuhkan sikap ta'awun (tolong menolong) antara keduabelah pihak. Itupun tetap dalam batasan-batasan yang sangatketat. Mulai dari caraberpakaian yang menutupauratsampailarangantabarruj(berh iasberlebihandiruangpublik),yang memungkinkanmunculnyahajatseksuallaw anjenisnya. Islam juga melarangwanita berduaandenganlaki-laki yang bukan mahramnya(khalwat).

Jelaspula,

binatang bila ia melanggar hukum Tuhan, sebagaimana Firman Allah Q.S. at-Tiin: 4-6

${ }^{28}$ ZinadalambahasaInggrisdisebutadultery.LihatLedenMarp aung,KejahatanTerhadap

KesusilaandanMasalahPrevensinya(Jakarta:SinarGrafika,1996), Cet.I,h.42. PadaKamusBesar Bahasa Indonesia, katazinamemuat duaarti:Pertama, perbuatan antaralaki-laki danperempuan

yangtidakterikatolehhubunganpernikahan(perkawinan);Kedua, perbuatanbersenggamaseorang lakilakiyangterikatperkawinandenganseorangperempuanyangterikat perkawinandenganseorang lakilakiyangbukansuaminya.LihatKamusBesarBahasaIndonesiah. 108.Adapunpengertianzina

menurutagamaIslamadalahsemuabentukpersetubuhandi luarnikahantaralaki-lakidanperempuan. Tidak diperhitungkan apakah salah satu atau keduanya sudah pernah menikah atau belum,

dalamperkawinanatautidak, danapakahperbuatantersebutdilakuk anatas dasarsukasamasukaatau tidak.LihatIsnawatiRais,TindakPidanaPerzinaanMenurutIslam, dalammajalahTabligh(Volume

02Nomor04,November2003),h.10
dalamIslamindustriataubisnisseksualatauy ang mengeksploitasipornografidiharamkan,tid ak perduliapakahitumenghasilkanuang atautidak.DalamIslam,uangbukanlahsegal anyauntukmenghalalkansegalacara.

Semua ini akanmenghindari munculnya seksbebas ditengah-tengah masyarakat. Karenaitusiapapunyang melanggaraturanaturantersebutakandiberikansanksinya secarategasdalamIslam. ${ }^{29}$

\section{PENGERTIANPENDIDIKANSEKSIS LAMI}

Pendidikan seks dapat diterjemahkan ke dalam bahasa Arab sebagai alTarbiyyah al-Jinsiyyah تينجا

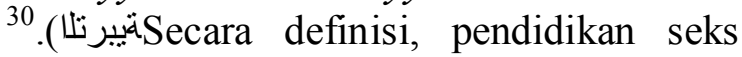
akandipaparkanolehbeberapapemerhatiseks ualitasmuslim,diantaranyayaitu:

AbdullahNasihUlwanmengatakanbah wa pendidikanseksadalahupaya pengajaran, penyadaran danpenerangan tentang masalah-masalah yang berkenaan dengan seks, naluri dan perkawinan. Sehingga jika anaktelahtumbuh menjadi seorangpemudadandapatmemahamiurusanurusankehidupan,iatelahmengetahui masalah-masalahyang diharamkandanyang dihalalkanbahkanmampumenerapkan tingkahlakuIslamisebagaiakhlakkebiasaand an tidakakanmengikutisyahwatdan caracarahedonisme. ${ }^{31}$

AbdulAzizEl-Qussy,menyatakan

bahwapendidikan seksialahpemberian pengalamanyangbenar

\footnotetext{
${ }^{29}$ Bagi pezina ghoiru muhshan (yang belum menikah), sangsinya dicambuk $100 \mathrm{kali}$, disamping ituKhalifah boleh menambahsanksihukuman dengancaramengasingkannya (taghrib) selama satu tahun. Sementara bagi pezina muhshan (yang sudah menikah) dirajamsampaimati. Sementara bagipelakuhomoseksual sanksinya adalahdibunuhbaiksudahmenikahataupunbelum. Untuk pelaku bisnis haram atau menyebarluaskan pornografi akan dikenakan sanksi ta'zir, yang hukumannya diserahkan pada pengadilan. Lihat FaridWajdi, http//www.hayatulislam.net/comments.net/

${ }^{30}$ Lihatbuku $\frac{\text { al-Tarbiyyahal-Jinsiyyahlial-Athfâlwaal- }}{2}$ BâlighînolehYusufMadan,dan al-Tarbiyyahal-JinsiyyahfialIslâmlial-Fatayâtwaal-FatayânolehUtsmânThawîl.

${ }^{31}$ AbdullâhNasîhUlwân,PedomanPendidikanAnakdalamIsla m,(terjmh:at-Tarbiyahlial-Aulâdfîal-Islâm),(Bandung:AsySyifa, 1988),h.572
} 
kepadaanak,agardapatmembantunyadalam menyesuaikan diridalamkehidupannyadi masa

depan.Sebagaihasildaripemberianpengala man

kepadaanak,dananakakanmemperolehsikap mentalyangbaikterhadapmasalah seksdanmasalahketurunan. ${ }^{32}$

Pendapat Gawshi sejalan denganpendapat Ulwan,menurutnya pendidikan seks adalahpemberian pengetahuan yang benarkepada anakdan menyiapkannya untuk beradaptasi secarabaik dengan sikap-sikap seksual dimasa depan kehidupannya. Pemberianpengetahuan ini menyebabkananak memperolehkecenderunganlogisyang benarterhadapmasalahmasalahseksualdanreproduksi. ${ }^{33}$

PembahasanseksdalamIslamtersebar dan dibahasbersamaandengan pendidikanlainnya.Ketikamembahastentan gakhlak(sistemmoral),seks merupakan bagianyangdikomentari.Contohnyaadalaha khlak,pergaulanantarpria danwanita. Ketikamembahasmengenaiibadah,sekskem balimenjadibagianyang dikomentari. Contohnya adalahwajibshalatbagiindividu yangtelahbaligh,mandijunubbagi

orangyangselesaihaid,

bersenggamaataumimpibasah.Ketikamemb ahasmengenai akidah(keimanan),kembaliseksmenjadibagi anyangdikomentari.FirmanAllahSWTdala mQ.S.al-Ahzâb[33]:35.

Dengandemikan,pendidikanseksdala mIslamadalahsatupaket dengan pendidikan nilai lainnya. Pemisahan pendidikan seksdaripesan-pesan nilai Islam akan berakibat hilangnya sasaran yanghendakdicapaidalampembinaanmoralI

\footnotetext{
${ }^{32}$ AbdulAzizEl-Qussy,PokokPokokKesehatanJiwa/Kesehatan MentalII,(AlihBahasa: ZakiahDaradjat),(Jakarta:BulanBintang,1975),Cet.I,h.281

${ }^{33}$ Yusuf Madani, Pendidikan Seks untuk Anak dalam Islam, (Tejmh: at-Tarbiyah al- Jinsiyyahlial-athfalwaal-Balighin), (Jakarta:PustakaZahra,2003),Cet.I,h.91
}

slam.

Berbeda dengan pendidikan seks dalammasyarakat Barat. Swedia sebagainegaraBaratyangpertamakalimemp erkenalkanpendidikanseks dengancara sistematis, dimulai sekitar tahun 1926, mengalami kegagalan. Bahkan pendidikan seks yang diterapkan tersebut berdampak negatif, karena semakin meningkatnya jumlahaborsi,selainitu

dampaklainnyaadalahgerejatelahditinggalk anpara pemeluknya karenaagamatelahdianggap kunodantidaklagidapatmemecahkan persoalanpadamasyarakatmodern. ${ }^{34}$

Memahamipendidikanseksdalampers pektifBaratharuspula melihatlatar belakangkemunculannya.Pendidikanseks padamasyarakatBaratadalah

dilatarbelakangioleh krisismoral seks masyarakat,makinmenjamurnyapelacuran, penyebaranpenyakitkelamindanpenyimpan ganseks, sertaminimnyapengetahuan masyarakatdalampengetahuanseks,kesehat anreproduksidankontrasepsi. ${ }^{35}$

PendidikanseksyangbaikmenurutKar tonoMuhammadtidakhanyaterbataspada pelajarananatomi(ilmuuraitubuh)danfisiolo gireproduksi(bagiantubuhyang berhubungandenganmasalahmereproduksi anak)saja, tetapijugameliputi perkembangan perilaku seksual manusia. Oleh karena itu pendidikan seks harusdilengkapidenganpendidikanetika. ${ }^{36} \mathrm{P}$ endidikan tentanghubungan antarasesama manusia, baik dalam keluarga maupun dalam masyarakat. Dalam pendidikan mengenaietikaini tercakuppulapandanganmoralitasdarisegia

\footnotetext{
${ }^{34}$ AliAkbar,SeksualitaDitinjaudariHukumIslam,h.16

${ }^{35}$ MarzukiUmarSa'abah,P erilakuSeksMenyimpang,h.246

${ }^{36}$ Kataetika berasal daribahasaYunani Kuno,dalambetuktunggal ethosyangberarti: tempattinggal yangbiasapadangrumput,kandang,kebiasaan,adat,akhlak,watak,p erasaan,sikap,

dancaraberfikir.Dalambentukjamak(taetha)artinyaadatkebiasaan Etikasecaraistilahberartinilai atau norma-norma mengenai benar dan salah yang dianut suatu golongan atau masyarakat. LihatSuwito,PendidikanAkhlakIbnMiskawaih.,h.19
} 
gama. $^{37}$

\section{KESIMPULAN}

Daripemaparan diatas, dapatditarik kesimpulan bahwadorongan seks itubersifatbiologis,naluriah, dan berlaku bagisemuaorang.Islamtidakmenekanhasrat seksmanusia,namunhasrat sekstersebutharuslahdiarahkankepadasesu atuhal yang positif,yaituuntukmengatur,mensejahterak an, danmempertahankan kehidupandi dunia,yaitumelaluilembagaperkawinan.Ap abilapengendaliandiri,dalamhalini imandanintelegensianyalemah,maka dorongansekstersebutbisamenguasaidiriny a untukmelakukantindakantindakanyangtidakwajar,termasukzina(per zinahan).

\section{DAFTAR PUSTAKA}

Rais, Isnawati, "Tindak Pidana Perzinaan Menurut Islam" dalam Majalah Tabligh (Volume 02 Nomor 04, November 2003)

Ulwân, Abdullah Nasîh, Pedoman Pendidikan Anak Dalam Islam, (Bandung: Asy- Syifa, 1988)

El-Qussy, Abdul Aziz, Pokok-Pokok Kesehatan Jiwa/Kesehatan Mental II, (Alih Bahasa: Zakiah Daradjat), (Jakart: Bulan Bintang, 1975)

Madani, Yusuf, Sex Education For Children, (Terjmh: At-Tarbiyyah al-Jinsiyyah li al-athfal wa alBalighin), (Bandung: Mizan, 2004),

Akbar, Ali, Dr.H, Seksualita Ditinjau dari Hukum Islam, (Jakarta: Ghalia Indonesia, 1986

Erich From, Revolusi Harapan, (Yogjakarta: Pustaka Pelajar, 1999) Gunarsa, Singgih D., Psikologi Praktis, Anak, Remaja dan Keluarga, (Jakarta: PT. BPK Gunung Mulia, 1991)

${ }^{37}$ SoerjonoSoekanto,et.al,MengenaldanMemahamiMasalahR emaja(Jakarta:Pustaka Antara,1991),Cet. I,h.110
Surviani, Istanti, Membimbing Anak Memahami Masalah Seks, (Bandung: Pustaka Ulumuddin, 2004)

Athâr, Shâhid, Bimbingan Seks Bagi Remaja Muslim, (Terjmh: Sex education: an Islamic Perspective), (Jakarta: Pustaka Zahra, 2003)

Departemen P \&K, Kamus Besar Bahasa Indonesia, (Jakarta: Balai Pustaka, 1996),

Soekanto, Sorjono, Mengenal dan Memahami Masalah Remaja, (Jakarta: Pustaka Antara, 1991),

Suwito, Konsep Pendidikan Akhlak Menurut Ibn Miskawaih, disertasi yang tidak diterbitkan, (Jakarta: IAIN Jakarta 1995 / 1996)

Sa'abah, Marzuki Umar, Perilaku Seks Menyimpang dan Seksualitas Kontemporer Umat Islam, (Yogyakarta: UII Press, 2001) ------, Seks dan Kita, (Jakarta:

Gema Insani Press, t,th)

Muhammad al-Zuhaili, Menciptakan Remaja Dambaaan Allah (Terjmh: al- Islâm wa al-Syabâb), (Bandung: Mizan, 2004), Cet ke-1, h. 123

John M. Echols, et.al, Kamus InggrisIndonesia, (Jakarta: PT.Gramedia, 1996),

James Drever, Dictionary of Physicology, (Jakarta: PT. Bina Aksara, 1988),

Abu Zakaria, Mengawetkan Cinta Kasih Suami Istri, (Solo: Aneka, 1990)

John M. Echols, et.al, Kamus InggrisIndonesia, (Jakarta: PT.Gramedia, 1996),

As'ad al-Kalali, Kamus Indonesia -Arab, (Jakarta: Bulan Bintang, 1997),

James Drever, Dictionary of Physicology, (Jakarta: PT. Bina Aksara, 1988),

Abu Zakaria, Mengawetkan Cinta Kasih Suami Istri, (Solo: Aneka, 1990),

Nasaruddin Umar, Kodrat Perempuan dalam Islam, (Jakarta: Fikahati Aneska, 2000), 
Peter Salim, Advanted English-Indonesia Dictionary, (Jakarta: Modern English Press, 1993),

WJS. Poerwadarminta, Kamus Umum Bahasa Indonesia, (Jakarta: Balai Pustaka, 1985),

Mustafầ Abdul Wahid, Islam dan Anarsisme Seks, (Yo19 yakarta: AlKautsar, 1990),

Ajen Dianawati, Pendidikan Seks Untuk Remaja, (Tangerang: Kawan Pustaka, 2003),

Abdullah Puar, Bimbingan Sex Untuk Remaja, (Jakarta: Pustaka Antara, 1996),

Ahmad Warson Munawwir, al-Munawwir; Kamus Bahasa Arab-Indonesia, (Yogyakarta:Pondok Pesantren alMunawwir, 1984), h. 1359.

Peter Salim,The Contemporary EnglishIndonesia: Dictionary, (Jakarta: Modern English Press, 1996), h. 1305. John M.Echols, Kamus Inggris-Indonesia, h.407 